\title{
Patrick Thériault, Le (dé)montage de la fiction: la révélation moderne de Mallarmé
}

\section{Maria Emanuela Raffi}

\section{OpenEdition}

\section{Journals}

\section{Edizione digitale}

URL: http://journals.openedition.org/studifrancesi/5722

DOI: 10.4000/studifrancesi.5722

ISSN: 2421-5856

\section{Editore}

Rosenberg \& Sellier

\section{Edizione cartacea}

Data di pubblicazione: 1 septembre 2011

Paginazione: 446-447

ISSN: 0039-2944

\section{Notizia bibliografica digitale}

Maria Emanuela Raffi, «Patrick Thériault, Le (dé)montage de la fiction: la révélation moderne de Mallarmé», Studi Francesi [Online], 164 (LV | II) | 2011, online dal 30 novembre 2015, consultato il 08 janvier 2021. URL: http://journals.openedition.org/studifrancesi/5722 ; DOI: https://doi.org/10.4000/ studifrancesi.5722

Questo documento è stato generato automaticamente il 8 janvier 2021.

\section{(c) $($ ) $(9)$}

Studi Francesi è distribuita con Licenza Creative Commons Attribuzione - Non commerciale - Non opere derivate 4.0 Internazionale. 


\title{
Patrick Thériault, Le (dé)montage de la fiction: la révélation moderne de Mallarmé
}

\author{
Maria Emanuela Raffi
}

\section{NOTIZIA}

PATRICK THÉRIAULT, Le (dé)montage de la fiction: la révélation moderne de Mallarmé, Paris, Champion, 2010, 350 pp.

1 Diviso in quattro parti, il denso saggio di Patrick THÉRIAULT presenta anzitutto una riflessione sul contributo agli studi mallarmeani dato dalle opere di Pierre Bourdieu, in particolare da Les Règles de l'art, in cui appare l'immagine di un Mallarmé lucido pensatore che pratica «le démontage impie de la fiction» nel momento stesso in cui egli sembra «donner à fond dans le culte de l'absolu». Ciò che in questa ambiguità mallarmeana si rivela, secondo Bourdieu, è la presenza del desiderio come motore primordiale della letteratura: nessuna verità appare dalla decostruzione della fiction, ma solo il desiderio «désespéré» del soggetto di confrontarsi con una verità assoluta, sia pure per rivelarne l'assenza. La modernità di Mallarmé appare proprio in questa capacità di fare della disillusione una tecnica espressiva e di portarne i risultati alle estreme conseguenze: «il ne "révèle" rien d'autre que le rien, soit le primat du symbolique et l'économie de la jouissance».

2 Nei tre capitoli successivi Thériault propone l'applicazione di queste riflessioni, cominciando con la lettura di «Salut» («La révélation de la fiction: pratique du sens et économie du désir chez Mallarmé»), cui attribuisce un «statut doublement révélateur»: sul piano della referenzialità e su quello dell'intersoggettività cioè nell'atto della scrittura e in quello della lettura. Chiamato in causa dai due nodi interpretativi cruciali della poesia - "la noyade des sirènes" della prima strofa («métaphore déroutante») e la sequenza «nous naviguons, ô mes divers/Amis [...]» della seconda strofa («communauté 
de la navigation poétique»)-il doppio statuto del testo produce ad un tempo un'oscurità concettuale irriducibile e una "provocazione" seduttiva all'interpretazione.

Il secondo capitolo («Théorie de la fiction et fiction de la théorie: la trame secrète des Dieux antiques») mostra il funzionamento parallelo di fiction e mitologia nella libera traduzione del trattato di mitologia dell'inglese George Cox, Les Dieux antiques, con particolare riferimento alla figura archetipale del sole. Cultore di mitologia comparata (diffusa in particolare da Max Müller) - che thériault accosta metodologicamente al «jeu enfantin sur les familles de mots»-, Mallarmé assume il punto di vista scientifico del testo di partenza, ma con una modernizzazione della forza del simbolo dovuta al «pouvoir mythopoétique du langage». E con una vistosa negazione: il nome di Müller scompare dalla traduzione, ma la sua "scienza" appare in piena luce per un'utilizzazione estetica anziché epistemologica.

«Mallarmé, sujet de la révélation», terzo ampio capitolo, prende in esame la critica della soggettività che porta da una parte all'impersonalità del discorso mallarmeano $\mathrm{e}$ dall'altra al ruolo di "grand initié» che il poeta senza dubbio ha impersonato. Lo statuto stesso del soggetto nei testi poetici appare fortemente problematico e "fantomatico", costruito com'è solo attraverso una realtà linguistica: «Dès lors que l'être se résorbe dans les mots [...] on ne le trouve jamais que dans les lieux du Discours, encore que ce soit sous la forme minimale de traces». E tuttavia questo soggetto frammentato e quasi inafferrabile appare incarnato nel mito del Libro, che dovrebbe "donner à lire», appunto, l'immagine fantasmatica di un soggetto, ma che, necessariamente, non può che limitarsi a "suggerirla".

5 Nel quarto capitolo, conclusivo, («Cas de figure, cas de fiction: le texte mallarméen et l'interprétation») Thériault pone il problema dell'interpretazione dell'opera di Mallarmé, messa in crisi dalla natura stessa del testo mallarmeano, rappresentazione per eccellenza dell'«indécidable» e di una chance di lettura fondata sul dubbio e sul hasard. 